\title{
Harvesting in electric vehicles: Combining multiple power tracking and fuel-cells
}

\author{
Juan-Gerardo Parada-Salado ${ }^{1}$, Luis-Fernando Gaona-Cárdenas ${ }^{2}$, Martín-Antonio Rodríguez-Licea ${ }^{3}$, \\ Francisco-Javier Perez-Pinal ${ }^{4}$ \\ ${ }^{1,2,4}$ Instituto Tecnológico de Celaya, Departamento de Ingeniería Electrónica, México \\ ${ }^{3}$ CONACYT-Instituto Tecnológico de Celaya, Departamento de Ingeniería Electrónica, México
}

\section{Article Info}

Article history:

Received Mar 19, 2020

Revised Apr 12, 2020

Accepted Apr 23, 2020

\section{Keywords:}

Circuit design

Electric vehicle

Energy harvesting

Energy management strategy

Parallel DC-DC converter

ABSTRACT

Exploitation of green energy sources is essential to diminish the deterioration of our environment. The energy harvesting, represents an alternative to achieve greater range in electric and hybrid vehicles. An energy management strategy (EMS) must be optimized to obtain the best benefits in such vehicles, which is not a trivial task. If harvesting or energy recovery devices are added, the EMS becomes a dual-purpose algorithm: minimizing fuel consumption and maximizing energy harvest through maximum power point tracking (MPPT) controllers. Known studies consider separate EMS, one for traction and another for regenerative braking, without considering harvest devices such as solar panels, regenerative suspension, thermal generators, among others. Furthermore, the electronic power converters used, are not designed to handle such unequal power levels. In this article, an electronic platform to include multiple energy harvesting devices in a fuel-cell hybrid electric vehicle, was presented together with a multiple MPPT-EMS. The EMS is easily implementable, and considers quasi-constant cell energy extraction and filtering of current transients to the battery bank ensuring the longevity of the devices. A new mathematical model of the platform, a closed loop stability analysis, and numerical and Hardware-in-the-Loop (HIL) validations were presented. Some experimental validation results were also provided.
\end{abstract}

Copyright (C) 2020 Insitute of Advanced Engineeering and Science. All rights reserved.

\section{Corresponding Author:}

Martín-Antonio Rodríguez-Licea,

Departamento de Ingeniería Electrónica,

CONACYT-Instituto Tecnológico de Celaya,

Antonio García Cubas 600, Fovissste, 38010 Celaya, Guanajuato, México.

Tel: +52-461-611-7575 Email: martin.rodriguez@itcelaya.edu.mx

\section{INTRODUCTION}

Nowadays, the importance of migrating mobility to greener environments and integrating it into the electric networks is well known, due to the impending deterioration of the planet [1]. Unfortunately, for private mobility, electric vehicles (EV) are not yet a viable option for the average consumer for two reasons, their high cost and/or their low range (miles per charge) with respect to internal combustion vehicles [2]. Wide range and low cost are variables closely related to the capacity of the BB used in EV and alternatives are currently being sought; one of these alternatives, is the integration of power generating sources to maintain and even raise the state of charge (SoC) while the EV circulates [3], such as solar panels [4-7], hydrogen fuel cells (HC) [8-13], biofuel engines [14, 15], hybrid motorization [16, 17], electric generating dampers [18-23], wireless recharge $[24,25]$, among others.

Unfortunately, the combined and simultaneous use of energy sources in EVs has been studied only for particular cases (do not consider several energy harvesting possibilities together with $\mathrm{HC}$, BB and SC) 
or it is not considered that the $\mathrm{BB}$ and the $\mathrm{HC}$ can degrade under conditions of overload or current demand transients [26-29]. In [30] the authors considered AC (kinetic energy, motion or electromagnetic radiation) and DC (thermal or solar) harvest devices/collectors; their proposed energy management strategy (EMS) uses the output voltage and a reference to set the output to the MPPT and selects an appropriate operating mode based on the power delivered and demanded. Unfortunately, they only considered 4 collectors of very low power. The authors of [31] studied a solar panel, a BB and two modes of operation for an EMS. For the first mode it was considered that the panel does not supply enough power and the BB is used until the maximum current point in the inductor is reached. In the second mode, it was considered that the power of the panel is much greater than that desired by the load such that the inductor current reaches its highest point and begins to decrease, this allows the BB to be charged with the remaining current in inductor. The authors of [32], proposed a double input and double output converter with Pulse Width Modulation (PWM) controls and a single inductor. The MPPT was used as a determining variable of the modes of operation; while the power of the panel is greater than the power of the load, the energy of the panel is transferred to the load and in turn to the BB. When the power of the panel is less than the power of the load, the strategy use a supplementary state in which the BB will feed the load.

In [33] a strategy of energy recycling was proposed considering a solar panel and a BB that feed a load by a double input double output converter with single inductor. The strategy used the MPPT and a higher voltage selector to generate the PWM pulses. The authors in [34] and [35] presented similar topologies and control strategies based on the detection of zero crossing in voltage or current to integrate two energy collectors to a DC load; experimental evidence was presented showing the effectiveness of the strategy. A non-isolated multi-input single output converter with three MOSFET switches per stage, that can operate in Buck or Boost mode independently, was presented in [36]. The authors presented a mathematical model, but they do not seem to consider stability, equalization or decoupling effects and do not proposed an EMS. In [37] the authors provided a control strategy for the integration of two solar panels with the power grid and power a load. In such research, the high power factor is essential for the development of an MPPT strategy and the switches were activated at zero-voltage and zero-current thus reducing the power losses. The article presented in [38] proposed a peculiar configuration for several power supplies such as a solar panel, a HC and a BB. In order to regulate the output voltage, the authors proposed a non-isolated converter topology with a minimum number of components, and an EMS that stands out for its easy implementation. In [39] the authors presented a configuration of $n$ boost stages in parallel, decoupled by the primary inductor of a transformer to perform the MPPT. A mathematical model and its analysis in a stable state were presented to establish a control strategy that allows simultaneous operation; unfortunately, the use of a transformer implies additional losses and the strategy does not guarantee that a BB, an $\mathrm{HC}$, neither a SC operates simultaneously.

It should be noted that in none of the papers reviewed, the integration of an unlimited number of energy collectors is performed for simultaneous operation with an EMS that manages to reduce the additional degradation to which the power sources can be subjected, including an hydrogen or fuel cell. That is, it is recommended that the BB does not absorb the current transients ([40-42]), that the solar panel and other collectors operate in the MPPT ([43]) and that the fuel cell provides a quasi-constant current at its nominal capacity ([44]). In addition, the development of such a system is a relevant problem under study by various research groups because the combined use of various energy sources in an EV has a direct benefit not only in its scope, but in the use of green energy sources.

Even more, from the state-of-art revision above, there are still many problems related to the integration of energy harvesting devices in an electric or hybrid electric vehicle. In this article, an alternative solution to the problem of selecting a platform that allows the use of a solar cell and a battery bank, together with multiple harvesting devices in an electric vehicle is presented (power electronic platform and the EMS algorithm sketch). This alternative considers minimizing degradation of the fuel cell and the battery bank due to peaks in the demanded power, which according to the manufacturer, cause its premature degradation. Also, the maximum power generation from the harvesting devices is ensured.

This article presents the following contributions to the state of the art:

(a) A new mathematical model is obtained for a $n$ stages, bidirectional Boost-Buck converter operating in $\mathrm{CCM}$, that allows the operation of SCs, BBs, regenerative braking motors and multiple energy harvest/storage devices simultaneously in an EV.

(b) The effects of equalization and decoupling of the stages of the proposed converter are analyzed. This allows to integrate sources of any power levels. 
(c) An experimental validation of the model.

(d) A stability analysis is performed and includes the dynamics of a bounded output controller.

(e) A MPPT, EMS for an EV with the proposed converter, based on design principles that include the prevention of premature degradation of the $\mathrm{BB}$ and $\mathrm{HC}$, is designed. The EMS is modular, low cost of implementation and can be scaled to include other harvesting devices.

(f) Semi-experimental tests (real-time simulations with hardware involved or Hardware-In-the-Loop HIL) are presented for the validation of the mathematical model and the energy management strategy, from which can be inferred the implementation of the EMS at low monetary cost.

This article is organized as follows. The system configuration, description and its analysis are presented in Section 2. Numerical, HIL, and experimental results are presented in Section 3. In Section 4 is presented a brief discussion and some conclusions.

\section{SYSTEM CONFIGURATION AND DESCRIPTION}

A general scheme of the proposed converter configuration for the power stage of the harvesting EV is shown in Figure 1. This configuration can be used for different scenarios, therefore, a general analysis of this circuit is presented first and then particularized to the EMS. In the left part of the circuit of Figure 1, there are several collectors/energy sources, connected in parallel to the CD Bus by means of a voltage amplification stage, better known as Boost converters. The collectors/sources include a solar panel, a HC, an energy-generating damper (EGD) and other sources (e. g. by vibration, heat, etc.) The last two are considered DC signals (rectified). In this way, the number of collectors is not limited, and, by having a modular design, collectors with their respective stages can be removed or added. On the other hand, at the bottom of the schematic, there are the energy storage devices (BB and SC) and finally the motor of the EV. These last three devices are connected to the DC bus through two-way (bidirectional) converters that function as a voltage reducer or Buck type from the DC bus to the device and as a Boost from the device to the DC bus. In this way, the BB and SC can be operated independently, and regenerative braking is allowed.

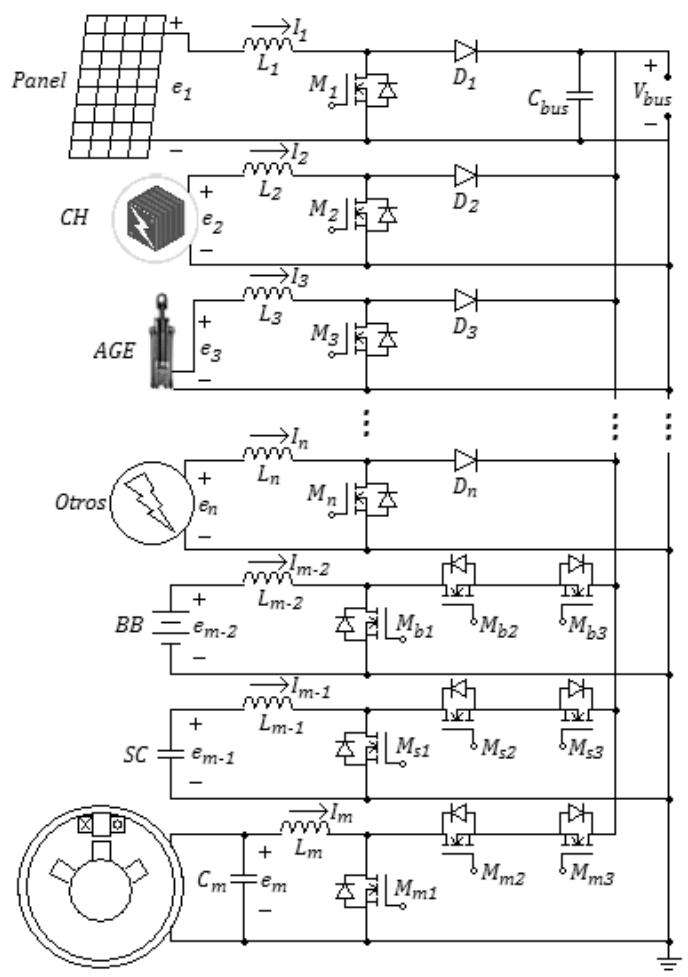

Figure 1. Schematic of the general $n$ stages, parallel converter for the platform. The circuit consist of paralleled, bidirectional stages type Boost to load and Buck back if required 


\subsection{Mathematical model of the converter}

The circuit of Figure 1 can be analyzed with a resistive load that demands power from the DC bus powered by $n$ devices. The motor, BB and SC can also provide energy and therefore increase the maximum $n$-th subscript. An averaged model obtained in continuous conduction mode (CCM) is:

$$
\begin{aligned}
L_{1} \dot{I}_{1} & =-u_{1} V_{\text {bus }}+e_{1} \\
L_{2} \dot{I}_{2} & =-u_{2} V_{\text {bus }}+e_{2} \\
& \vdots \\
L_{n} \dot{I}_{n} & =-u_{n} V_{\text {bus }}+e_{n} \\
C_{\text {bus }} \dot{V}_{\text {bus }} & =u_{1} I_{1}+u_{2} I_{2}+\ldots+u_{n} I_{n}-\frac{V_{\text {bus }}}{R_{\text {bus }}} \\
L_{m-1} \dot{I}_{m-1} & =-e_{m-1}+u_{m-1} V_{\text {bus }} \\
C_{m-1} \dot{e}_{m-1} & =I_{1}+I_{2}+\ldots+I_{n}-I_{m}-I_{m-2}-\frac{e_{m-1}}{R_{m-1}} \\
L_{m} \dot{I}_{m} & =-e_{m}+u_{m} V_{\text {bus }} \\
C_{m} \dot{e}_{m} & =I_{1}+I_{2}+\ldots+I_{n}-I_{m-1}-I_{m-2}-\frac{e_{m}}{R_{m}}
\end{aligned}
$$

where $R_{\text {bus }}$ is the equivalent resistance to the load connected on the bus and $R_{m-2}, R_{m-1}$ and $R_{m}$ the equivalent resistances of the stages. From the equations in (1), it should be noted that duty cycles in stationary dynamics, depend inversely on $V_{\text {bus }}$ :

$$
\begin{array}{r}
u_{1}=\frac{e_{1}}{V_{\text {bus }}} \\
\vdots \\
u_{n}=\frac{e_{n}}{V_{\text {bus }}}
\end{array}
$$

where $1-\widehat{u}_{i}=u_{i} i=1, \ldots, n$. If the work/duty cycle of stage $0 \leq \widehat{u}_{i} \leq u_{\max } \approx 0.8$ is less than the equations (2), the current flow through the diode $D_{i}$ is negligible due to the lower potential at the anode, leaving the stage isolated (it will not provide current to the load) regardless of the values of the components $\left(u_{i}\right.$ is used as the inactive cycle.) Similarly, if the current of the source $e_{i}$ is not enough to match the voltage $V_{b u s}$ the stage will be isolated by the diode. This intrinsic equalization is beneficial in the case of an EV, since the BB regularly has the greatest capacity to provide current while protecting the integrity of the other devices by not requiring a current greater than they can provide.

\subsection{Converter closed loop stability under arbitrary switching}

The time derivative of the bus voltage in (1) with $0<u_{\min } \leq u_{i} \leq 1$, for $i=1, \ldots, n$, where $u_{\min }$ is the minimum value of the inactive cycle (approximately 0.2 and limited by physical characteristics of the components) is:

$$
C_{b u s} \ddot{V}_{b u s}=-a \dot{V}_{b u s}-b V_{b u s}+c
$$

where

$$
\begin{array}{r}
a=\frac{1}{R_{\text {bus }}}>0 \\
b=\frac{u_{1}^{2}}{L_{1}}+\ldots+\frac{u_{n}^{2}}{L_{n}}>0 \\
c=\frac{u_{1} e_{1}}{L_{1}}+\ldots+\frac{u_{n} e_{n}}{L_{n}}>0
\end{array}
$$

Rewriting on state space representation and shifting to the operating point (recall that $u_{i}>0$, hence $b>0$ ) $x_{1}=V_{\text {bus }}-\frac{c}{b}, x_{2}=\dot{V}_{\text {bus }}$ one has :

$$
\dot{x}=A x
$$


where

$$
A=\left[\begin{array}{cc}
0 & 1 \\
-b & -a
\end{array}\right] \text {. }
$$

Consider controllers $0<u_{i}(t)=k_{i} V_{\text {bus }} \leq 1$ to regulate the bus voltage to a reference $V_{\text {ref }}$; the state equations are:

$$
\begin{array}{r}
\dot{x}_{1}=x_{2} \\
\dot{x}_{2}=-\kappa x_{1}^{3}-a x_{2}
\end{array}
$$

where

$$
\kappa=\frac{k_{1}^{2}}{L_{1}}+\ldots+\frac{k_{n}^{2}}{L_{n}}>0
$$

and $k_{i}>0 \forall i=1 \ldots n$ are the controller gains. To demonstrate stability in the sense of [45], consider a Lyapunov candidate function $V=\frac{1}{4} x_{1}^{4}+d \frac{1}{2} x_{2}^{2}$ with $d>0 ; V(0)=0, V(x)>0 \forall x \neq 0$ and its derivative along the system paths (5) is represented by:

$$
\dot{V}=x_{1}^{3} x_{2}(1-d \kappa)-d a x_{2}^{2}
$$

Selecting $d=1 / \kappa$ one has

$$
\dot{V}=-\frac{a}{\kappa} x_{2}^{2}<0, \forall x_{2} \neq 0
$$

and then the stability of the closed loop system is demonstrated.

Even more, $\kappa(t)>0$ for all $k_{i}(t)>0$ and it is easy to show that an MPPT control is a $u_{i}(t)=$ $k_{i}(t) V_{\text {bus }}$ controller $\left(k_{i}(t)=f_{i}\left(I_{i}(t)\right)\right)$; hence, the stability with multiple MPPT controllers for feasible values of $u_{i}(t)$ in the proposed platform is demonstrated.

\subsection{Multiple MPPT energy management strategy}

In the scenario proposed in the previous section, it is now necessary to establish an EMS that complies with several design principles; EMS must:

(a) Maintain the BB's SoC from the available energy sources.

(b) Be computable in real time.

(c) Take advantage of all the energy available from the harvesting devices (MPPT) that do not use consumables (i.e. the solar panel, EGDs, etc.) and ultimately that obtained from the HC.

(d) Allow the $\mathrm{HC}$ to provide current to a quasi-constant and limited regime due to its intrinsic operation.

(e) Achieve that the SC absorbs rapid energy demand transients to prevent premature BB and HC damage.

(f) Allow regenerative braking.

With regard to criterion 5, it should be mentioned that large current transients have been shown to cause early degradation in BBs and HCs, regardless of their chemistry (see for instance [40]). Since the motor can provide energy when performing regenerative braking, the EMS is divided into acceleration and regenerative braking modes as discussed below.

\subsubsection{EMS in acceleration mode}

The block diagrams of the proposed EMS are depicted in Figure 2. A configuration that allows compliance with the design principles mentioned, and in acceleration mode is shown in Figure 2 (a). Although the diagram of the basic converter as depicted in Figure 1 shows the BB connected to the DC bus through a two-way Buck-Boost stage, for the proposed EMS such a stage is not necessary and connects directly to the DC bus of the load that includes the $\mathrm{SC}$ and $R_{L}$ with its Buck and Boost stages respectively; in this way, the $\mathrm{SC}$ will soften the demand for energy towards the BB and HC. In addition, the connection of an SC to the bus allows the decoupling of the stages, making the equalization shown in equations (2) unnecessary; that is, in this way the duty cycles will not depend on the voltage on the bus to achieve a current control per stage. For the present work, the $\mathrm{BB}$, the $\mathrm{SC}$ and $R_{L}$ constitute the variable load $R_{b u s}$ that depends on the driving conditions (of the vehicle) as shown in Figure 2 (a). 


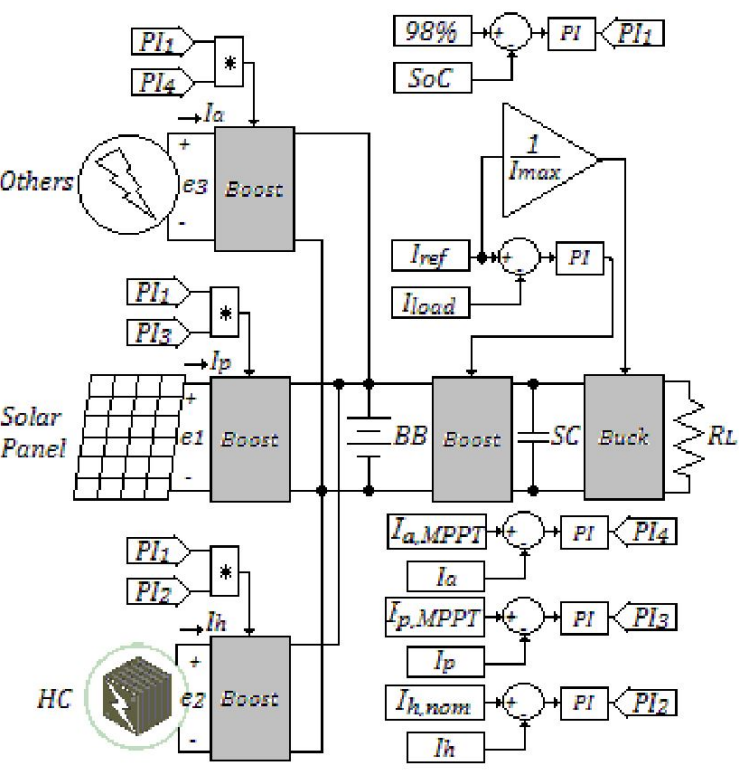

(a)

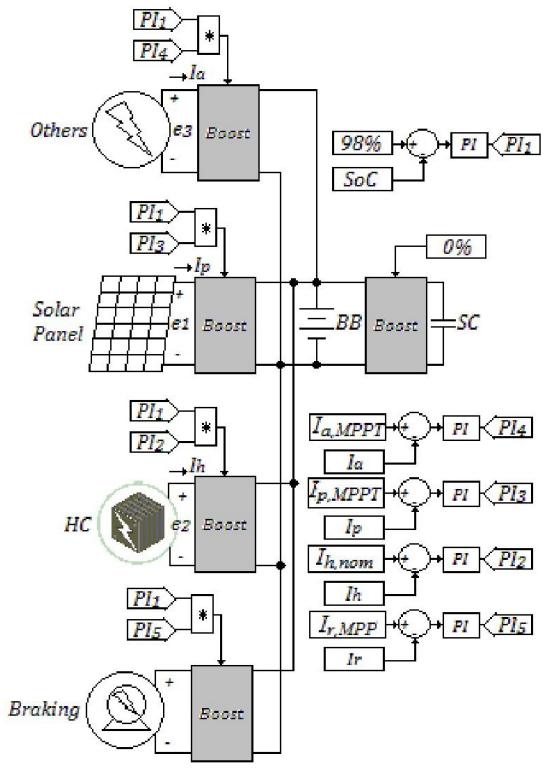

(b)

Figure 2. Block diagram of the proposed EMS (a) in acceleration mode and (b) in regenerative braking mode. The motor is switched to power sources side, by an interrupter in the brake pedal (relay). This block diagram is possible for the general converter of Figure 1 by making $L_{m-2}=0$ and $M_{b 2}=1$, and integrating a variable speed regulator (Buck converter) at motor (slowly variable load)

Since the BB is connected to the DC bus, $\dot{V}_{b u s} \approx 0$ can be considered (stationary state); that is to say, it is of much slower dynamics and therefore from (1) one has:

$$
V_{\text {bus }}=R\left(u_{1} I_{1}+u_{2} I_{2}+\ldots+u_{n} I_{n}\right)
$$

provided that $u_{i} \geq \frac{e_{i}}{V_{b u s}}$. In other words, the direct connection of the BB to the CD bus allows decoupling the $n$ stages to achieve the injection of current independently.

On the other hand, the load that is now modeled as a resistor (motor winding) and is connected to the SC through a Buck converter while the BB is connected to the SC through a Boost stage; in this way it is ensured that the voltage in the SC is at least the potential of the BB in steady state and the regulation of current demanded by the driver of the EV denoted as $I_{r e f}$ is allowed. A proportional-integral controller (PI) allows regulating the duty cycle of the Boost converter from $\mathrm{BB}$ to $\mathrm{SC}$ and in turn functions as a low-pass filter of the current demanded to the $\mathrm{BB}$, thus complying with the criterion (e).

The SoC is regulated by a PI controller with output $P I_{1}$ that will seek to maintain $98 \%$ (criterion (a)); it is not set to $100 \%$ to ensure that it is not overloaded causing premature degradation [28]. Cascade controllers with proper tuning allow the MPPT from the energy sources (criteria (c) and (d)) and delay the use of the HC, in order to properly establish the duty cycles of each of the Boost stages on the left side of the DC bus. Proper tuning (slow action) allows a quasi-constant current regime to be extracted from the HC (criterion (d)). The current references $I_{a, M P P T}, I_{p, M P P T}$ (and the others that are necessary when extending the configuration) can be obtained through commercial circuitry or dedicated software and $I_{h, n o m}$ is obtained from the manufacturer. $I_{a}, I_{p}$ and $I_{h}$ represent the RMS value of current supplied by the auxiliary (other), solar panel and $\mathrm{HC}$ respectively. Under this configuration, other energy harvesting and energy storage devices can be easily attached.

\subsubsection{EMS in regenerative braking mode}

To comply with the criterion (f), the converter can be easily reconfigured using a contactor/relay as shown in Figure 2 (b). This setting is activated by a switch on the brake pedal that puts the bi-directional converter of the motor stage in Boost mode where $I_{r, M P P T}$ represents the MPPT current reference. 
Until now, the strategy has been shown that can comply with all design principles except for the (b) that is implementation-related. The implementation for real-time operation, being simple controllers for both modes of operation of the proposed EMS, does not represent a technical difficulty using even low-cost digital signal processing (DSP) micro controller devices. In the following section, it is demonstrated that it is possible to implement both the controller and the model of each of the devices involved in real time with integration time of $6 \mu s$.

\subsection{SoC control stability}

In order to verify the stability under the action of the proposed controller for SoC (which differs from the MPPT control stability presented before because of the integral action), the state of charge of the BB can be estimated as:

$$
S o C=S o C(0)+\frac{100}{Q} \int I_{i} d t
$$

where $Q$ is the nominal capacity of the BB. From (1) and (8), $u_{i}$ represents the inactive cycle, so a PI controller with reference $r$ can be defined as:

$$
u_{i}=1-k_{i, p}(r-S o C)-k_{i, i n t} \int(r-S o C) d t
$$

Then the differential equations for the parallel stages (of the converter), as a function of (8), (9) and (10) are:

$$
\ddot{S o} C=\frac{-V_{b u s} k_{i, p} S \dot{o} C-V_{b u s} k_{i, i n t} S o C+V_{b u s} k_{i, i n t} r}{0.01 L_{i} Q}
$$

Clearing SoC(s) of the Laplace transform from the previous equation:

$$
S o C(s)=\frac{V_{b u s} k_{i, i n t} r / s}{\frac{L_{i} Q}{100} s^{2}+V_{\text {bus }} k_{i, p} s+V_{b u s} k_{i, i n t}}
$$

Using the Routh Hurwitz criterion it is easy to demonstrate that the system is stable for some positive gain values.

\subsection{Dimensioning and Output Ripple}

From voltage balances in steady-state and CCM operation for each stage (as regularly used for single Boost stages), one can obtain:

$$
L_{i}>1.2 \frac{D_{M} R_{L}\left(1-D_{M}\right)^{2}}{2 f}
$$

where $D_{M}$ is the maximum duty cycle and $f$ is the PWM frequency; a $20 \%$ increment is selected for ensure CCM.

The voltage ripple in the BB can be conservatively determined as:

$$
\Delta V_{B B}=\frac{V_{B B} D_{M}}{R_{B B} C_{B B} f}
$$

where $V_{B B}$ is the nominal voltage of the $\mathrm{BB}$ and $R_{B B}$ and $C_{B B}$ are the equivalent resistance and capacitance in the BB.

\section{NUMERICAL SIMULATIONS AND EXPERIMENTAL RESULTS}

In this section, are presented HIL, and experimental validations of the mathematical model. Subsequently, HIL simulations are included that demonstrate the effectiveness and ease of implementation of the EMS. 


\subsection{HIL Validation of the mathematical model}

To validate the mathematical model obtained, several simulations were performed in Simulink and the dynamic response is compared with the circuit emulated in HIL; this is, Typhoon HIL402 platform include realistic models of solar panels, batteries, electronic devices as MOSFETs, among others, that allows validating the analytic model (numerically solved in Matlab). This Python-based, compact 4-core HIL gives all the tools to test power electronics controllers in a wide range of applications as solar and wind power generation, battery storage, power quality and motor drives; also, this device allows to test controllers in real time with $20 \mathrm{~ns}$ PWM resolution, in closed loop with high-fidelity power stage with $1 \mathrm{MHz}$ update rate. Here, only representative results are provided. The Typhoon HIL402 platform is used to emulate the converter stages in real time with an integration time of $6 \mu \mathrm{s}$. Sources of 48,24 and $12 \mathrm{~V}$ are used with capacities of 8,8 and $6 \mathrm{Ah}$ respectively, $2.2,2.0$, and $2.5 \mathrm{mH}$ for $L_{1}-L_{3}, C=200 \mu \mathrm{F}$ and $R=10 \Omega$ with $V_{b u s}=60 \mathrm{~V}, u_{1}=0.20, u_{1}=0.60$ and $u_{1}=0.80$.

Figure 3 shows the comparisons of the output voltage $V_{\text {bus }}$ and the currents in the inductors $I_{1}-I_{3}$ obtained from the HIL emulation against the dynamic responses of the mathematical model. Although there is a transitional stage with a longer duration in the mathematical model, the final voltage value is $60 \mathrm{~V}$ on average. It should be noted that the transient is of longer duration because in the HIL emulation the voltage sources are modeled BBs with limited current capacity, while in the mathematical model the current provided by the sources is unlimited. In the lower trends it can be seen that the average of the currents in the inductors in the HIL emulation is very close to the value of the currents obtained by the numerical integration of the mathematical model. In this way it could be concluded that the mathematical model is a conservative representation of the transitory while stationary error when comparing the response with an HIL platform is $2.5 \%$ on average.
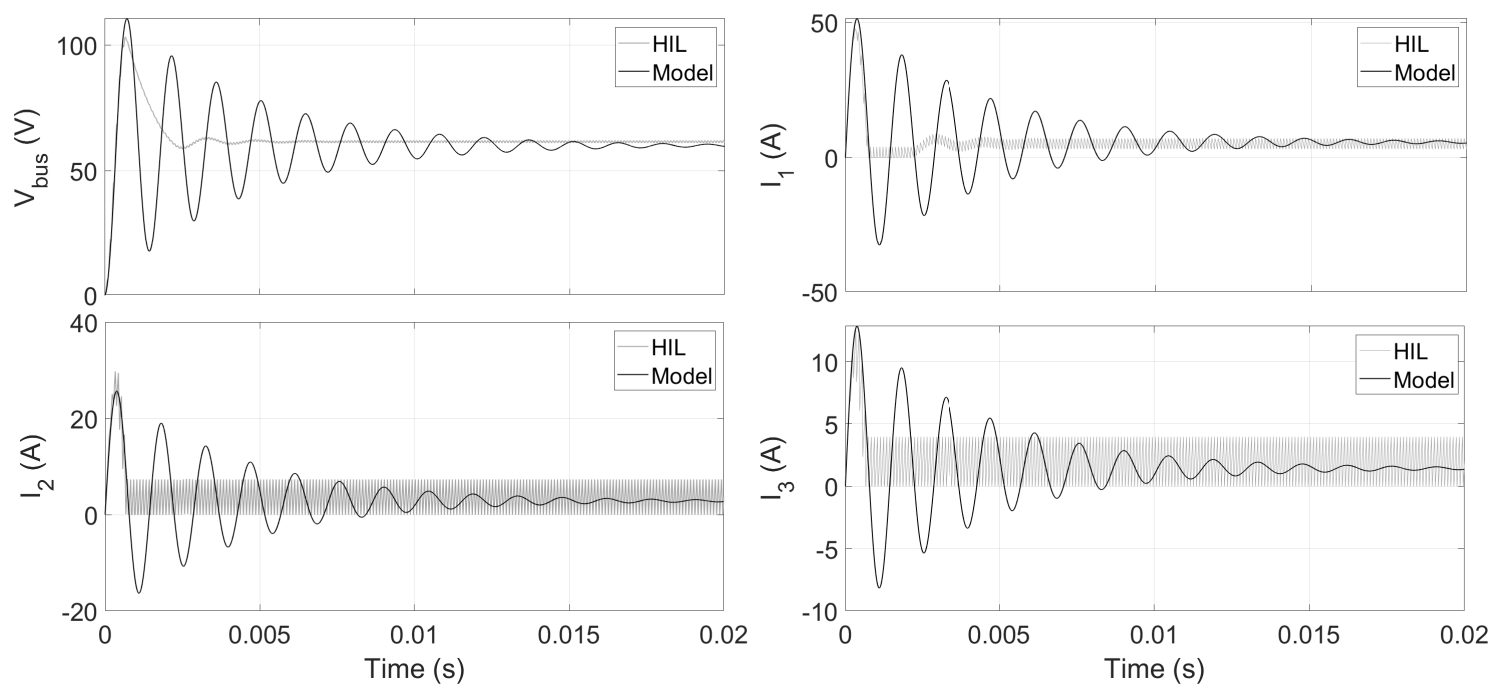

Figure 3. Comparison of the dynamic response of the converter, obtained from the averaged mathematical model vs HIL emulation (switched). The average dynamics have minimal error in steady state.

The transitional stage is slightly different because the power sources in the model are ideal whereas in the HIL tests they are battery models; In addition, the dynamics of the diode are neglected in the model (the currents in the inductors cannot be negative)

\subsection{Experimental validation of the mathematical model}

In order to validate the model and the mentioned equalization phenomenon, an experimental platform as depicted in Figure 4 is built for the general converter of Figure 1. A DSPIC30F4011 is used to generate the PWM signals, $15 \mu \mathrm{H}$ inductors (5711-RC) are calculated for $D_{M}=0.5$ and $f=20 \mathrm{kHz}$ with three $5 \mathrm{~V}$ sources and a $50 \mu F$ capacitor is calculated for a 0.1 voltage ripple. In Figure 5 is shown a comparative of the numerical against experimental behavior in the output voltage; note that the average error is only about $5 \%$ for equalized duty cycles. In Figure 6 are shown the inductor currents for the same test; note that all stages operate in CCM. 


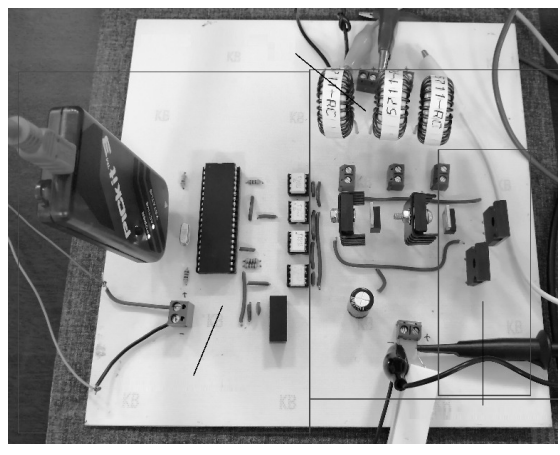

Figure 4. PCB of the experimental setup. PWM and control can be implemented in a DSPIC30F, which results in a economical and effective proposal

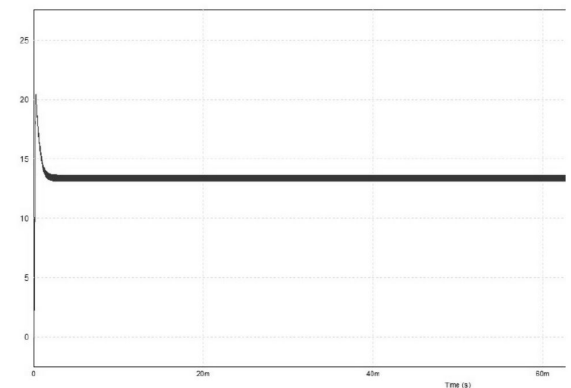

(a)

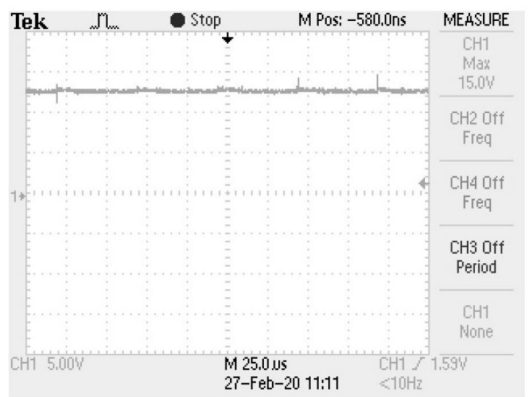

(b)

Figure 5. Output voltage comparison, (a) numerical against (b) experimental with equalized duty cycles. The steady state error is minimal for the average voltage, about $2 \%$

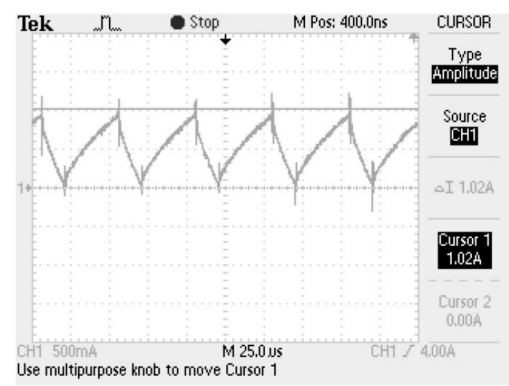

(a)

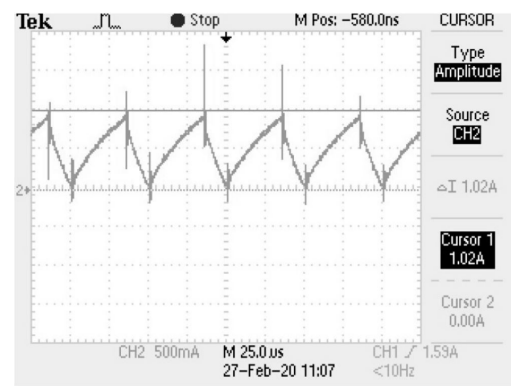

(b)

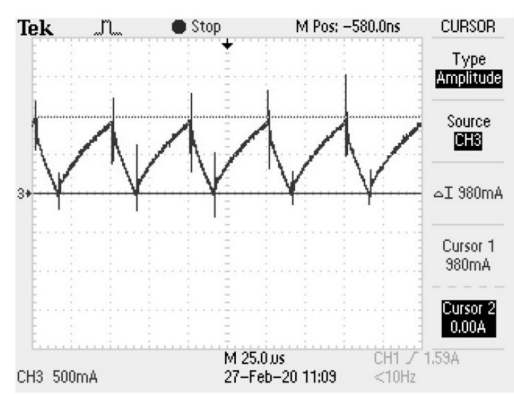

(c)

Figure 6. Inductor current in (a) $L_{1}$, (b) $L_{2}$, and (c) $L_{3}$ with equalized duty cycles. All inductor currents describe a CCM operation since (2) are met 
Below, comparisons are presented under the same conditions as the previous one, but with the nonequalized duty cycles $(0.4,0.5$ and 0.6 respectively). The Figure 7 shows the comparison of the output voltage and in Figure 8 the currents in inductors are shown. Notice how when the cycles are not equalized, only one inductor remains operating in CCM while the others operate in DCM (the stage with greater duty cycle remains in $\mathrm{CCM}$ ); also, the output voltage value no longer matches the model.

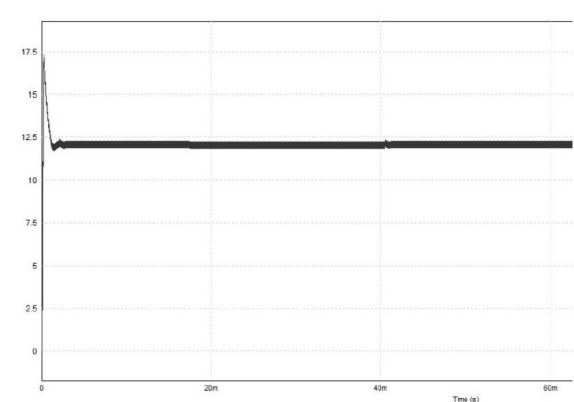

(a)

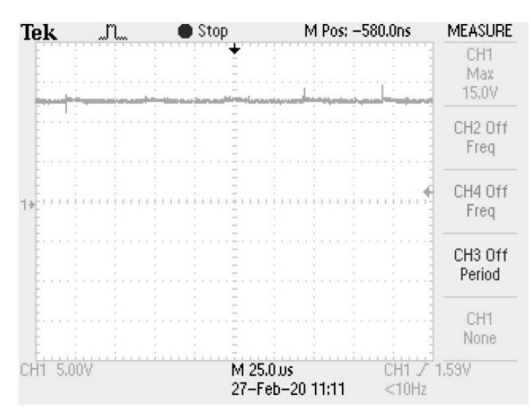

(b)

Figure 7. Output voltage comparison. (a) numerical and (b) experimental with no equalized duty cycles. The steady state error is large, about $15 \%$, since (2) are not met

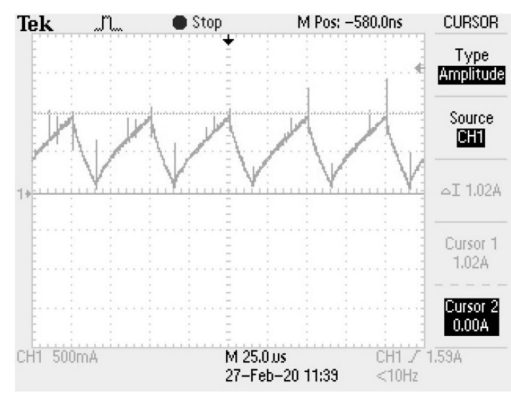

(a)

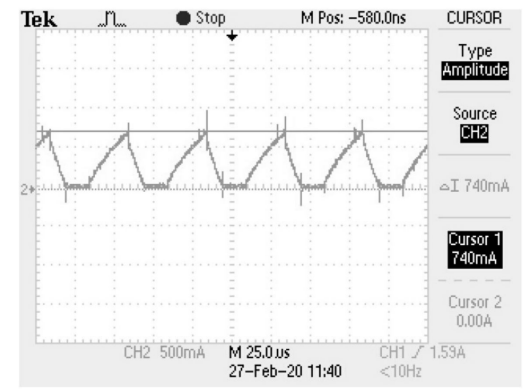

(b)

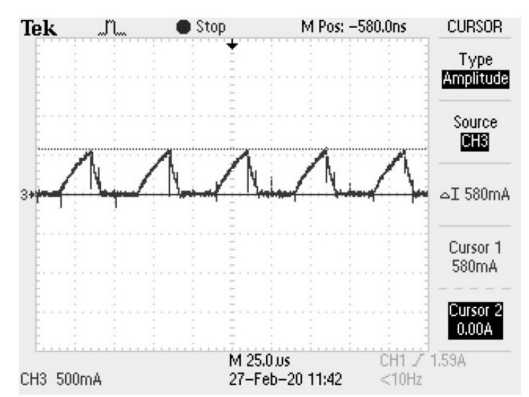

(c)

Figure 8. Inductor current in (a) $L_{1}$, (b) $L_{2}$, and (c) $L_{3}$ with no equalized duty cycles. Only the equalized stage(s) (stage 1) operates in CCM, the rest operates in DCM

\subsection{Validation of the EMS}

To perform the tests of the proposed EMS, it is implemented together with the mathematical model of each source device, on the Typhoon HIL platform; this allows to show that the EMS is real-time computable, and at the same time that it shows the correct operation of the EMS with realistic models of the devices. The current reference is provided by an external voltage source to the Typhoon emulating the position of the EV throttle. Typhoon HIL includes a solar panel model whose characteristic curve with nominal voltage of 29.73 
$V$ and $112.37 \mathrm{~W}$ at constant irradiation of $500 \mathrm{~W} / \mathrm{m}^{2}$ (the maximum usable for the panel), so $I_{p, M P P T}=$ $3.76 \mathrm{~A}$. As a note, irradiation values of up to $1388 \mathrm{~W} / \mathrm{m}^{2}$ from 2014 to 2018 have been presented in this entity according to data from a state weather station; in México, the annual average is $5.3 \mathrm{kWh} / \mathrm{m}^{2}$ per day according to information from CONAGUA in 2012 ([46]). A $24 V$ at $41.6 A(1000 W)$ HC from Horizon brand is emulated; for this test HIL will be used to the maximum $\left(I_{h, n o m}=41.6\right)$, in a real scenario, a value recommended by the manufacturer should be used.

In addition, a harvest device that provides 19 volts of DC and a maximum current of $1 A$ is emulated $\left(I_{a, M P P T}=1 A\right)$. A BB bank of $48 V$ with capacity to $24 A h$ and with initial SoC of $95 \%$ is used. The inductors are selected of $2.2 \mathrm{mH}$ except for the inductor in the load converter, which is $10 \mathrm{mH}$, with $C_{\text {bus }}=300 \mu$ and a SC with capacitance of $1 F$. The capacitor of the Buck converter of the load is selected of $100 \mu \mathrm{F}$ and $R_{L}=1 \Omega$. PI controllers are tuned accordingly to the source, slow action for the fuel cell $\left(k_{p}=0.05, k_{i}=0.02\right)$ and fast response for MPPT controllers $\left(k_{p}=1.0, k_{i}=2.3\right)$. The SoC PI controller is tuned and stabilize the transfer function (12) with $k_{p}=0.05, k_{i}=0.01$. The converters operate at $20 \mathrm{kHz}$ and the driving/load profile presented in this paper, is an arbitrary 2-minute duration shown in Figure 9 along with the dynamic response of the current in the load. It can be seen that the current demand $I_{\text {ref }}$ is satisfied with a minimum tracking error; here, $I_{\max }=44.7 \mathrm{~A}$ is used, equivalent to approximately $2 \mathrm{~kW}$.

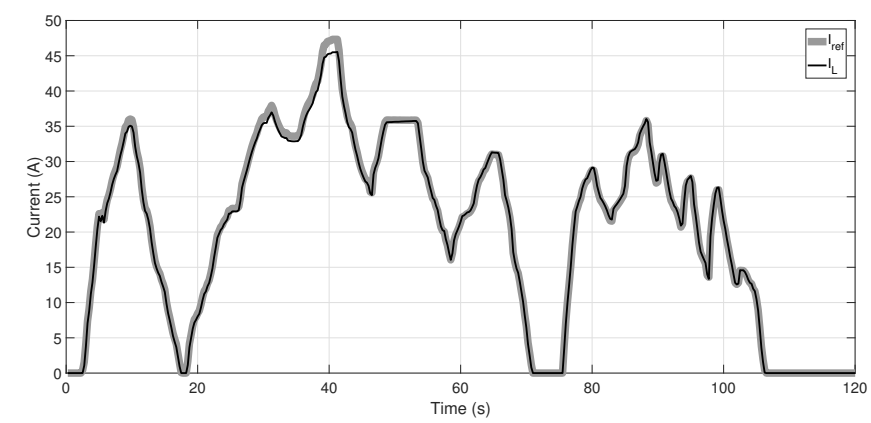

Figure 9. Comparison of demanded current against supplied. Even if the power demand is arbitrary, the EMS is capable of track such behavior while harvest devices are providing energy

The evolution of the SoC for the load profile is shown in Figure 10; a minimum decrease and early recovery under conditions of optimal energy harvesting can be noticed. Figure 11 shows the current contribution of each of the devices to recharge the BB. Note that an specific tuning for the type of HC could be necessary; this depends on manufacturer data. Figure 12 shows the charging current $I_{L}$ compared to that supplied by BB $\left(I_{b a t}\right)$ and that supplied by the SC $\left(I_{S C}\right)$; note that when the current is supplied by the SC, rapid changes in BB current are being absorbed. Figure 13 shows the evolution of the voltage in the bus $V_{b u s}$ against the voltage in the load $V_{L}$ and the voltage in $\mathrm{SC}\left(V_{S C}\right)$.

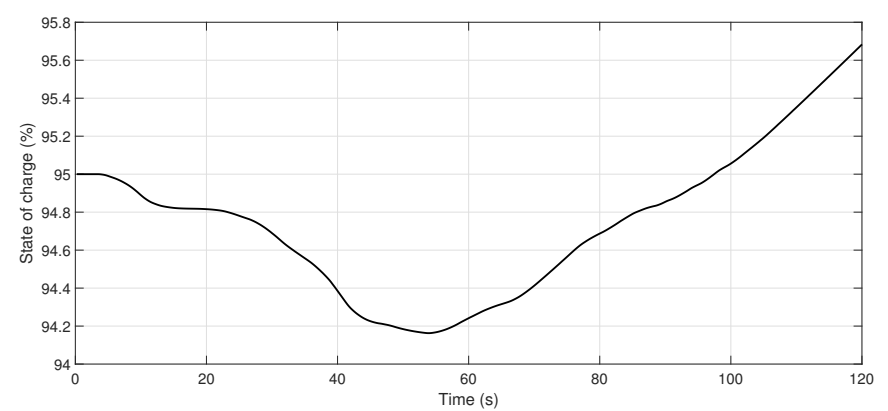

Figure 10. State of charge of the BB. Even if the power demand is arbitrary, the EMS is capable of track such behavior while harvest devices are providing energy to charge the battery bank 


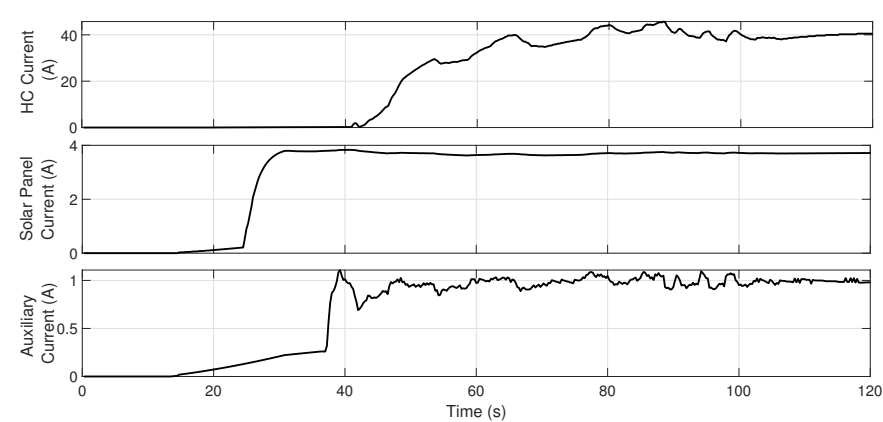

Figure 11. Charging currents of the BB. The tuning of the PI for the HC (upper plot) can be tuned to get an even more smooth dynamic if necessary. Clearly the MPPT can extract the maximum power of the solar panel and auxiliary (middle and bottom plots); note that auxiliary produces a low frequency, power supply behavior and the EMS can extract the MPPT

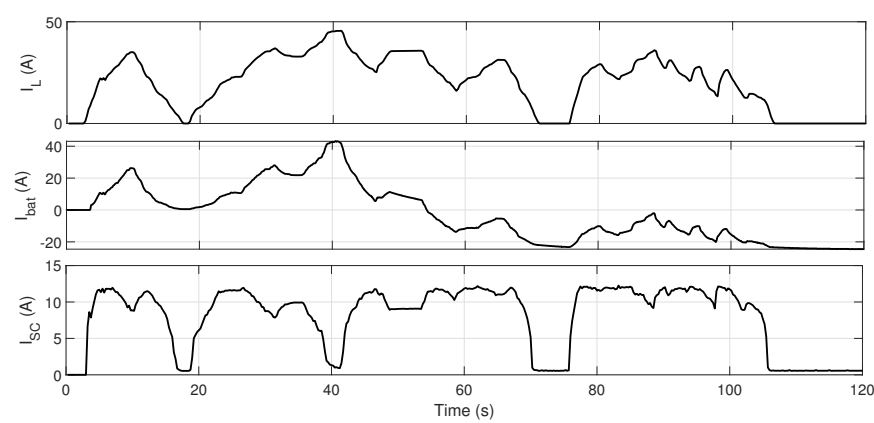

Figure 12. Load, BB, and SC currents (upper, middle and bottom plots respectively); when the load current is supplied, rapid changes in demand current are being absorbed by the SC

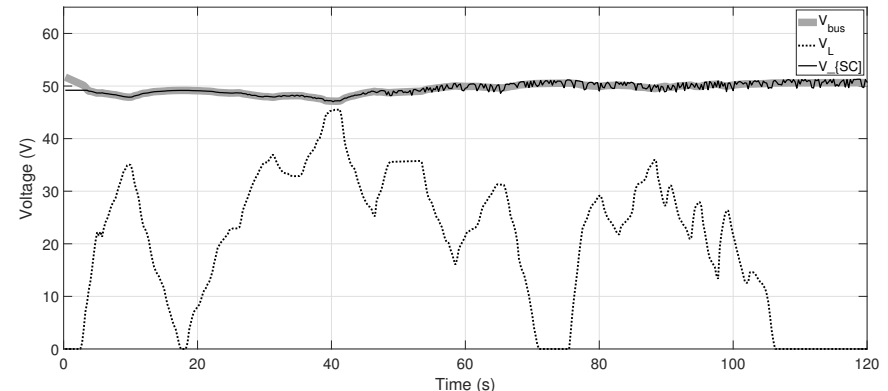

Figure 13. Voltage on the bus and on the load. A quasi constant voltage in the bus (upper plot) is beneficial for the BB to avoiding its premature degradation. A smooth voltage in the load (bottom plot) indicates a soft load response and hence a gentle driving of the EV

Next, comparative tests of the decay of the SoC are carried out under a constant regime of $85 \%$ demand to be able to notice the benefit of each of the collecting devices over 25 minutes. Figure 14 shows the comparison of the SoC that clearly indicates that the $\mathrm{HC}$, having a much higher capacity, is almost capable of maintaining the SoC; the solar panel and auxiliary/others modestly improve autonomy but do not require consumables or expensive maintenance. Table 1 shows a comparison of the decay of SoC, consumption of $\mathrm{H}$, approximate cost of $\mathrm{H}$ over the 25 minutes and the estimate cost of collectors. A density of $\mathrm{H}$ of $0.0708 \mathrm{~kg} / \mathrm{lt}$ and a cost of $1 U S D / l t$ of $\mathrm{H}$ is used. The cost that auxiliary collectors would have is not considered since they are still under development phase, not for sale in considerable current capacities. 


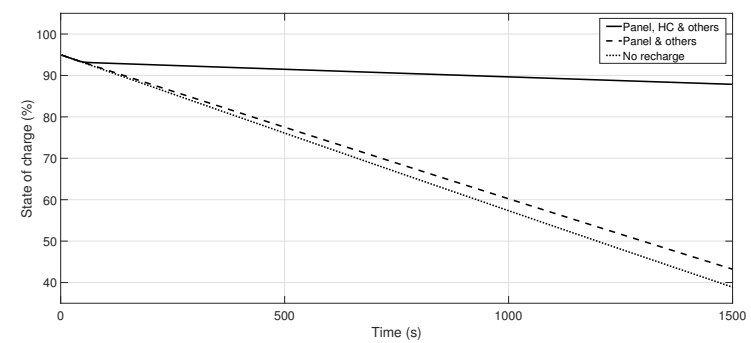

Figure 14. SoC at 25 minutes with $I_{r e f}=0.85 I_{\max }$. Using a single $500 \mathrm{Wh}$ solar panel in conjunction with a single $19 \mathrm{Wh}$ collection device, reduces the discharge of a 24 Ah battery bank by $5 \%$ in 25 minutes at a rate of $85 \%$ of maximum speed in a small Electric Vehicle $(\mathrm{EV})$

Table 1. Comparison of benefit and cost

\begin{tabular}{ccccc}
\hline Scenary & SoC fall & $\mathrm{H}$ & Cost $(\mathrm{H})$ & Harvest device cost \\
\hline HC+Panel+other & $7.07 \%$ & $22.12 \mathrm{~kg}$ & \$23.4 USD & \$4,070 USD \\
Panel+other & $51.7 \%$ & $0 \mathrm{~kg}$ & \$0 USD & \$200 USD \\
\hline
\end{tabular}

\section{DISCUSSION}

In this article is presented the analysis of a parallel Boost converter and an energy management strategy that is capable of achieve several design relevant principles. The dimensioning of the components is not the objective of this study and is an open topic for further studies. For instance, for a vehicle of certain dimensions and weight, there will be an optimal combination of energy capacities, costs and weights of the CH, PS, BB and other associated devices. Nevertheless, its possible to analyze the efficiency for each of the converters that are involved in the system, considering the switching losses due to the drain to source on-resistance $\left(R_{D S_{(o n)}}\right)$. In Table 2 is shown the theoretical percentage of individual efficiency calculated using:

$$
\eta=\frac{P_{\text {in }}-P_{\text {loss }}}{P_{\text {in }}}
$$

with SiC MOSFETs. On the other hand, at the moment it is clear that the use of hydrogen as an alternative source for an EV, is not affordable from the point of view of an average consumer since it implies large costs of investment, maintenance and payment of supplies, although other energy collecting devices are used simultaneously. However, the present work presents an advance in the sense of estimating, testing and integrating the sources of energy collection for simultaneous operation in an EV, regardless of when the scientific and technological progress allows to improve the efficiency of the harvesting devices and the electrical/electronic components.

Table 2. Efficiency per parameters

\begin{tabular}{ccc}
\hline Input source & $R_{D S_{(\text {on })}}(\Omega)$ & Efficiency \\
\hline Solar & 0.08 & $99 \%$ \\
Other & 0.08 & $99 \%$ \\
Hydrogen cell & 0.025 & $97 \%$ \\
Battery bank & 0.025 & $99 \%$ \\
Super-capacitor & 0.025 & $99 \%$ \\
\hline
\end{tabular}

\section{CONCLUSIONS}

In conclusion, this paper presents the modeling, stability analysis, equalization and decoupling effects of a parallel Boost converter of $n$ stages including $m$ bidirectional stages in the load side. In addition, a multiple MPPT EMS is developed and validated semi-experimentally. The EMS allows the maximum power extraction of multiple energy harvesting devices to recharge the BB online in an EV or a HEV. Also, the proposed configuration is capable of filtering current demand transients with high efficiency and hence avoid premature degradation of the $\mathrm{BB}$ and the $\mathrm{HC}$. Although at the moment the use of a $\mathrm{HC}$ is not convenient from an economic point of view, the strategy contemplates the use of other devices including those that do not provide energy continuously or of high magnitude as regenerative dampers, vibration generators and TMGs. 


\section{CONFLICTS OF INTEREST}

The authors declare no conflict of interest for this paper.

\section{FUNDING}

The authors are grateful for the funding granted by CONACYT for the 4155 Chairs and the scholarships of Gerardo and Luis.

\section{REFERENCES}

[1] N. R. Babu, Smart Grid Systems: Modeling and Control, 1st ed. Apple Academic Press, Inc., 2018.

[2] A. Pandey, S. Manocha, and P. Saini, "A study on an automobile revolution and future of electric cars in india," International Journal of Management (IJM), vol. 11, no. 3, pp. 107-113, 2020.

[3] Y. Cai and R. Beach, "Prospects of alternative fuels for future onroad transportation," in Proceedings of the 22nd Annual Conference on Global Economic Analysis. GTAP, 2019, p. 5.

[4] S. Nagaraj, R. Ranihemamalini, and L. Rajaji, "Performance enhancement of dc/dc converters for solar powered ev." International Journal of Electrical \& Computer Engineering (2088-8708), vol. 10, 2020.

[5] U. Yilmaz, O. Turksoy, and A. Teke, "Improving a battery charger architecture for electric vehicles with photovoltaic system,” International Journal of Energy Research, 2020.

[6] M. C. Mercan, M. Ö. Kayalica, G. Kayakutlu, and S. Ercan, "Economic model for an electric vehicle charging station with vehicle-to-grid functionality," International Journal of Energy Research, 2020.

[7] W. Yaïci, C. A. Hossain, N. Chowdhury, and M. Longo, "Optimization of solar energy system for the electric vehicle at university campus in dhaka, bangladesh," Energies, 2018.

[8] C. B. Robledo, L. B. van Leeuwen, and A. J. van Wijk, "Hydrogen fuel cell scooter with plug-out features for combined transport and residential power generation," International Journal of Hydrogen Energy, 2019.

[9] H.-S. Lee, M.-Y. Lee, and C.-W. Cho, "Analytic study on thermal management operating conditions of balance of $100 \mathrm{kw}$ fuel cell power plant for a fuel cell electric vehicle," Journal of the Korea AcademiaIndustrial cooperation Society, vol. 20, no. 2, pp. 1-6, 2019.

[10] S. Colnago, "Modelling fuel cell electric vehicle architectures for a comparative analysis," Ph.D. dissertation, Politecnico di Milano, Piazza Leonardo da Vinci, 3220133 Milano, Iitalia, 42019.

[11] A. Kheirandish, E. Akbari, M. Nilashi, and M. Dahari, "Using anfis technique for pem fuel cell electric bicycle prediction model," International Journal of Environmental Science and Technology, pp. 1-8, 2019.

[12] A. DeCandis, "Hydrogen fuel-cell electric hybrid truck demonstration," Houston-Galveston Area Council, Tech. Rep., 2018.

[13] A. P. Mohamed, K. V. Chandrakala, and S. Saravanan, "Comparative study of maximum power point tracking techniques for fuel cell powered electric vehicle," in IOP Conference Series: Materials Science and Engineering, vol. 577, no. 1. IOP Publishing, 2019, p. 012031.

[14] K. Tucki, R. Mruk, O. Orynycz, A. Wasiak, K. Botwińska, and A. Gola, "Simulation of the operation of a spark ignition engine fueled with various biofuels and its contribution to technology management," Sustainability, vol. 11, no. 10, p. 2799, 2019.

[15] A. Gounni, N. Rais, and M. A. Idrissi, "New solutions to reduce the environmental impact of road traffic emissions, using sumo," in Proceedings of the 2nd International Conference on Networking, Information Systems \& Security. ACM, 2019, p. 33.

[16] D. A. SERIN and M. Özpınar, "Modelling and simulation of driving performance in a series hybrid electric vehicle," in 9th International Automotive Technologies Congress, OTEKON 2018, 2018.

[17] L. Liu, L. Wang, and C. Dai, "Experimental study on influence factors of emission and energy consumption for plug-in hybrid electric vehicle," in International Conference on Frontier Computing. Springer, 2018, pp. 1863-1873.

[18] V. Tvrdić, S. Podrug, D. Jelaska, and M. Perkušić, "Regenerative hydraulic shock absorber for vehicle applications: prototype design," Energy Sources, Part A: Recovery, Utilization, and Environmental Effects, pp. 1-25, 2020.

[19] G. Vaičiūnas, N. Šešok, and I. Iljin, "Utilization of vibration energy from vehicle using smart damper," 
Automation 2020: Towards Industry of the Future: Proceedings of Automation 2020, March 18-20, 2020, Warsaw, Poland, p. 345, 2020.

[20] A. Dzedzickis, T. Lenkutis, M. Makulavičius, V. Bučinskas, and I. Morkvėnaitė-Vilkončienė, "Towards autonomous driving: Design of smart damper-energy harvester," Pomiary Automatyka Robotyka, vol. 23, 2019.

[21] R. Zhang, "A study of vehicle electromagnetic regenerative shock absorber," Ph.D. dissertation, RMIT University, 124 La Trobe Street, Melbourne VIC 3000, Australia, 52019.

[22] P. Zheng, R. Wang, and J. Gao, “A comprehensive review on regenerative shock absorber systems," Journal of Vibration Engineering \& Technologies, pp. 1-22, 2019.

[23] J. Zou, X. Guo, M. A. Abdelkareem, L. Xu, and J. Zhang, "Modelling and ride analysis of a hydraulic interconnected suspension based on the hydraulic energy regenerative shock absorbers," Mechanical Systems and Signal Processing, vol. 127, pp. 345-369, 2019.

[24] Y. D. Ko and Y. J. Jang, "The optimal system design of the online electric vehicle utilizing wireless power transmission technology," IEEE Transactions on Intelligent Transportation Systems, vol. 14, no. 3, pp. 1255-1265, 2013.

[25] F. Musavi and W. Eberle, "Overview of wireless power transfer technologies for electric vehicle battery charging," IET Power Electronics, vol. 7, no. 1, pp. 60-66, 2014.

[26] L. Cai, J. Meng, D.-I. Stroe, G. Luo, and R. Teodorescu, "An evolutionary framework for lithium-ion battery state of health estimation," Journal of Power Sources, vol. 412, pp. 615-622, 2019.

[27] S. K. Rechkemmer, X. Zang, W. Zhang, and O. Sawodny, "Empirical li-ion aging model derived from single particle model," Journal of Energy Storage, vol. 21, pp. 773-786, 2019.

[28] A. W. Thompson, "Economic implications of lithium ion battery degradation for vehicle-to-grid (v2x) services," Journal of Power Sources, vol. 396, pp. 691-709, 2018.

[29] S. Shinzaki, H. Sadano, Y. Maruyama, and W. Kempton, "Deployment of vehicle-to-grid technology and related issues," SAE Technical Paper, Tech. Rep., 2015.

[30] S. J. Oh, D. Khan, S.-H. In, R. E. Rad, I. Ali, S. Yeo, Y. Ryu, Y. Pu, and K.-Y. Lee, "A solar/thermoelectric/triboelectric/vibration/rf hybrid energy harvesting based high efficiency wireless power receiver," in 2019 26th IEEE International Conference on Electronics, Circuits and Systems (ICECS). IEEE, 2019, pp. 911-914.

[31] S.-H. Chen, T.-C. Huang, S. S. Ng, K.-L. Lin, M.-J. Du, Y.-C. Kang, K.-H. Chen, C.-L. Wey, Y.-H. Lin, C.C. Lee et al., "A direct ac-dc and dc-dc cross-source energy harvesting circuit with analog iterating-based mppt technique with $72.5 \%$ conversion efficiency and $94.6 \%$ tracking efficiency," IEEE Transactions on Power Electronics, vol. 31, no. 8, pp. 5885-5899, 2015.

[32] H. Shao, X. Li, C.-Y. Tsui, and W.-H. Ki, "A novel single-inductor dual-input dual-output dc-dc converter with pwm control for solar energy harvesting system," IEEE Transactions on Very Large Scale Integration (VLSI) Systems, vol. 22, no. 8, pp. 1693-1704, 2013.

[33] Y.-H. Wang, Y.-W. Huang, P.-C. Huang, H.-J. Chen, and T.-H. Kuo, "A single-inductor dual-path threeswitch converter with energy-recycling technique for light energy harvesting," IEEE Journal of Solid-State Circuits, vol. 51, no. 11, pp. 2716-2728, 2016.

[34] N. K. Reddi, M. R. Ramteke, H. M. Suryawanshi, K. Kothapalli, and S. P. Gawande, "An isolated multiinput zcs dc-dc front-end-converter based multilevel inverter for the integration of renewable energy sources," IEEE Transactions on Industry Applications, vol. 54, no. 1, pp. 494-504, 2017.

[35] S. Dusmez, X. Li, and B. Akin, "A new multiinput three-level dc/dc converter," IEEE Transactions on Power Electronics, vol. 31, no. 2, pp. 1230-1240, 2015.

[36] M. Azizi, M. Mohamadian, and R. Beiranvand, "A new family of multi-input converters based on three switches leg," IEEE Transactions on Industrial Electronics, vol. 63, no. 11, pp. 6812-6822, 2016.

[37] H. SRIDHARAN and S. Ramalingam, "Design and implementation of two-phase interleaved voltage source inverter for pv applications," IIUM Engineering Journal, vol. 20, no. 2, pp. 127-141, 2019.

[38] R. R. Ahrabi, H. Ardi, M. Elmi, and A. Ajami, "A novel step-up multiinput dc-dc converter for hybrid electric vehicles application," IEEE Transactions on Power Electronics, vol. 32, no. 5, pp. 3549-3561, 2016.

[39] J. Zeng, W. Qiao, L. Qu, and Y. Jiao, "An isolated multiport dc-dc converter for simultaneous power management of multiple different renewable energy sources," IEEE journal of emerging and selected topics in power electronics, vol. 2, no. 1, pp. 70-78, 2013. 
[40] M.-A. Rodríguez-Licea, F.-J. Perez-Pinal, A.-G. Soriano-Sánchez, and J.-A. Vázquez-López, "Noninvasive vehicle-to-load energy management strategy to prevent li-ion batteries premature degradation," Mathematical Problems in Engineering, vol. 2019, 2019.

[41] M. Woody, M. Arbabzadeh, G. M. Lewis, G. A. Keoleian, and A. Stefanopoulou, "Strategies to limit degradation and maximize li-ion battery service lifetime-critical review and guidance for stakeholders," Journal of Energy Storage, vol. 28, p. 101231, 2020.

[42] A. Barré, B. Deguilhem, S. Grolleau, M. Gérard, F. Suard, and D. Riu, "A review on lithium-ion battery ageing mechanisms and estimations for automotive applications," Journal of Power Sources, vol. 241, pp. 680-689, 2013.

[43] M. Kumar and A. Kumar, "Performance assessment and degradation analysis of solar photovoltaic technologies: A review," Renewable and Sustainable Energy Reviews, vol. 78, pp. 554-587, 2017.

[44] T. Stein and Y. Ein-Eli, "A critical review challenges and perspective of metal-based pem's bipolar platesexploring durability and longevity," Energy Technology, 2020.

[45] H. K. Khalil and J. W. Grizzle, Nonlinear systems. Prentice hall Upper Saddle River, NJ, 2002, vol. 3.

[46] N. Hernández-Cruz, "Relación entre el Índice de marginación y la irradiación solar," 2012.

\section{BIOGRAPHIES OF AUTHORS}

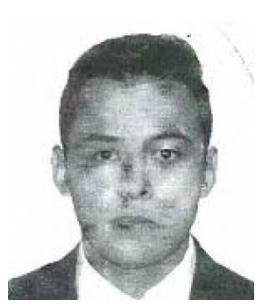

Juan Gerardo Parada Salado received the B.S degree in communication and electronics engineering from the National Polytechnic Institute (IPN), Mexico City, Mexico in 2015, and the M.Sc. degree, in electronics engineering in Technology Institute of Celaya (ITC), Guanajuato, Mexico, in 2018. His research is mainly in control an intelligent system area and actually is a Ph.D. student in the Technology Institute of Celaya.

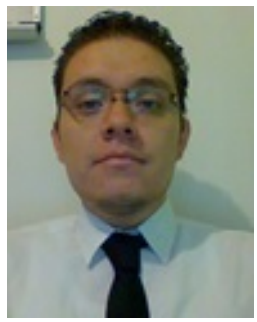

Luis Fernando Gaona Cárdenas is an Electronics Engineer from the Technological Institute of Celaya, has experience in the industry where he carried out electro-pneumatic projects and remote controllers for test benches and as an advisor in the development of technical manuals for companies such as Polygrapack. He has participated in competitions such as "Applying Mexico" and "Santander Award for business innovation" in addition to giving conferences at various institutions such as CETis and CBTis.

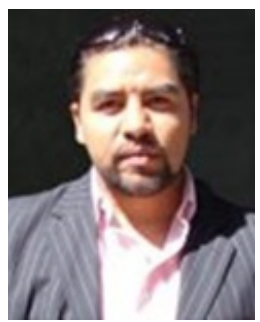

Francisco J. Pérez Pinal received the Ph.D. from the University of San Luis Potosí, San Luis Potosí, Mexico, in electrical engineering. He is a professor in the Department of Electronic Engineering, Technological Institute of Celaya, Celaya, Mexico. His research interests include power electronics, electric motors, renewable energy, smart grids, energy conversion systems, and transportation electrification.

Further info on: https://experts.mcmaster.ca/display/perezpif

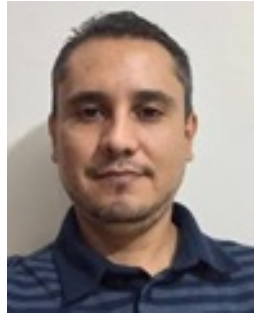

Martín Antonio Rodríguez Licea is a Doctor of Applied Sciences in Control and Dynamic Systems from the Potosino Institute of Scientific and Technological Research, member of the National System of Researchers (Level I) and CONACYT Professor assigned to the Technological Institute of Celaya. $\mathrm{He}$ is the author of more than 28 publications and his research lines are the intelligent generation and management of energy, dynamic modeling, stability and control of switched and time-variant systems.

Further info on: https://scholar.google.com.mx/citations?hlēs\&user0̄2_nzncAAAAJ 